\title{
Assessment and Promotion of Judicious Antibiotic Use on Dairy Farms in Washington State
}

\author{
M. J. Raymond, ${ }^{*}$ R. D. Wohrle, ${ }^{\star}$ and D. R. Call ${ }^{1}$ \\ ${ }^{*}$ Communicable Disease Control Program, Tacoma-Pierce County Health Department, Tacoma, WA 98418 \\ †Department of Veterinary Microbiology and Pathology, Washington State University, Pullman 99164
}

\begin{abstract}
The aims of this study were to describe antibiotic use and biosecurity practices among Washington State dairy producers and to evaluate the effectiveness of a collaborative approach to promoting judicious antibiotic use on dairy farms. In collaboration with a statewide industry group, Washington State dairy producers participated in a written, self-administered survey in 2003. They were then provided several educational interventions followed by a second written survey in 2005 . Sixtyfive percent (381) of dairy producers completed the 2003 survey. The most commonly cited drugs used for disease treatment were penicillin, ceftiofur, and oxytetracycline. Participants also indicated significant preventive uses with 28\% using medicated milk replacer. Most producers appeared to consider intramammary infusion at dry-off to be a treatment rather than a preventative practice. Twenty-three percent of initial respondents indicated at least one extra-label use of antibiotics, yet only half routinely consulted with a veterinarian when doing so. Most agreed that using written protocols for disease treatment could reduce errors, but less than one-third had protocols. After the educational intervention there was a tendency toward reduced use of antibiotic medicated milk replacer: $51 \%$ of producers who originally reported using medicated milk replacer discontinued this practice, whereas $12 \%$ of producers began using medicated milk replacer between the 2003 and 2005 surveys. Most reported that the resources and educational materials were useful. Areas where additional work is needed include reducing the use of medicated milk replacer, increasing veterinary involvement in antibiotic use decisions, implementing treatment protocols, enhancing biosecurity, and ensuring optimal cow and calf immunity.
\end{abstract}

Key words: antibiotic use, biosecurity, milk replacer

Received September 14, 2005.

Accepted March 21, 2006.

${ }^{1}$ Corresponding author: drcall@vetmed.wsu.edu

\section{INTRODUCTION}

Antibiotic-resistant pathogens remain a growing threat to human and animal health, and the use of antibiotics in animal agriculture has been implicated in generating and maintaining resistant pathogens (Witte, 1998; Anderson et al., 2003; Angulo et al., 2004). For example, a number of studies have demonstrated an association between antibiotic use and the occurrence of resistant enteric bacteria in chickens (Humphrey et al., 2005; Randall et al., 2005; Takahashi et al., 2005), cattle (Alcaine et al., 2005; Berge et al., 2005b; Sato et al., 2005), and swine (Dunlop et al., 1998; Delsol et al., 2004; Mathew et al., 2005). Consequently, nontherapeutic agricultural use of antimicrobial agents has been banned in several European countries, and bills have been introduced into the United States Congress to enact a similar ban (H.R. 2562, S. 742, 2005). The amount of antibiotic use in livestock is not known and is widely disputed (NRC, 1998; Mellon et al., 2001).

Selection pressure from agricultural use of antibiotics is one factor driving the evolution, maintenance, amplification, and horizontal spread of antimicrobial-resistant microbes and the genes that confer resistance (Aarestrup et al., 2001; Berge et al., 2005b; Poppe et al., 2005). This is thought to largely affect commensal organisms, but commensal organisms can cause opportunistic infections and may represent an important reservoir of resistance genes that can be shared with pathogenic organisms and thus have a direct effect on both animal and human health (Levy, 1978; Threfall et al., 2000; Aubry-Damon et al., 2004). In the dairy industry, the most common infectious diseases in heifers and cows for which antibiotic therapy can be indicated include mastitis, respiratory illness, lameness, and enteric diseases (Andrews, 2000; Dodd and Booth, 2000; Weaver, 2000). One of the largest uses of antibiotics in dairy production may be for "dry cow" treatment. This practice involves a long-acting intramammary antibiotic infusion given to cows between lactation cycles with the intention of treating existing infections and preventing new infections (Dodd and Booth, 2000; USDA, 2003b). It is worth noting that 2 retrospective surveys of antibiotic resistance found considerable vari- 
ation between mastitis agents, but no consistent change in the prevalence of antibiotic resistance despite nearuniversal use of antibiotics at cow dry-off (Erskine et al., 2002; Makovec and Ruegg, 2003). In calves, respiratory and enteric illnesses predominate (Andrews, 2000) and appear to be associated with the quality and quantity of colostrum received in the first $12 \mathrm{~h}$ after birth (Gay, 1984; Nocek, et al., 1984; Barrington et al., 2002). If insufficient colostrum is transferred to a calf, there will be an inadequate titer of protective antibodies and the calf will be susceptible to more disease problems (Wittum and Perino, 1995; Weaver et al., 2000; Arthington, 2001). It could be argued that poor colostrum management can indirectly encourage routine use of subtherapeutic and prophylactic antibiotics in feed and milk replacers.

Milk replacers (MR) are a ready source of nutrition for the neonatal calf, and their use is widespread in the American dairy industry. For example, $70 \%$ of dairy farms in Pennsylvania use medicated MR (Sawant et al., 2005). These products often contain antibiotics (medicated MR; Heinrichs et al., 1995) and some studies have shown that this practice can improve performance and reduce scours in dairy calves (Quigley et al., 1997). Nevertheless, the use of medicated MR has been directly implicated in increased shedding of drug-resistant strains of bacteria (Sawant and Jayarao, 2002; Berge et al., 2005a; Sato et al., 2005) and there are conflicting findings regarding the benefits from using medicated MR. Donovan et al. (2002) demonstrated that medicated MR was not superior at controlling calf scours compared with MR containing probiotics, allicin, and fructooligosaccharides. Morrill et al. (1995) found no growth advantage or reduction in scours in calves fed MR containing chlortetracycline over an antibioticfree product. Losinger et al. (1995) and Fossler et al. $(2005 a, b)$ reported an association between medicated MR and reduced risk of Salmonella shedding, whereas Wray et al. (1987) reported no association. In a recent study, Berge et al. (2005a) found that addition of highdose, in-feed antibiotics delayed onset of morbidity, increased overall weight gain, and decreased overall morbidity. Nevertheless, passive immune transfer via colostrum appeared to be the most important factor in limiting morbidity and mortality in these animals.

These findings emphasize the importance of adopting and maintaining good management practices in the absence of subtherapeutic and prophylactic treatments. Indeed, when the European Union banned use of avoparcin (1997) and bacitracin, spiramycin, tylosin, and virginiamycin (1999), there was a reported increase in therapeutic use of antimicrobial agents in food animals (Casewell et al., 2003), although there were concomitant reductions in prevalence of resistance in some ani- mal populations (Aarestrup et al., 2001). As noted by Berge et al. (2005a), effective passive transfer in cattle is more effective in reducing calf mortality and morbidity compared with subtherapeutic feed additives. The other control measure is biosecurity (Hancock et al., 2000). That is, many significant communicable diseases of cattle can be introduced into a herd by infected animals that are introduced to the premises (Faust et al., 2001; van Schaik et al., 2002; Grooms, 2004). Thus, preventing the introduction of pathogens onto the farm is one biosecurity strategy for limiting antibiotic use. However, very few dairy operations routinely quarantine incoming cattle (Faust et al., 2001; USDA, 2003a).

Despite the widespread use of antimicrobial drugs in animal agriculture, there is little information describing the knowledge and practices related to antibiotic use at the level of the agricultural producer. A recent article by Sawant et al. (2005) has begun to shed light on this topic. They found extensive use of antibiotics both for disease prevention and treatment in Pennsylvania dairy herds, with $\beta$-lactams and tetracyclines being the most commonly used classes. Few producers used treatment protocols, and many reported stopping treatment before completing a course of therapy.

Without a better understanding of the extent of antimicrobial application and a better understanding of the attitudes and practices of producers, it will be difficult to develop effective measures to reduce the use of antimicrobial drugs in US animal agriculture. Furthermore, biosecurity is an underappreciated strategy for reducing the need for therapeutic drug use in animal husbandry, and thus it is important to determine how dairy producers view and enforce biosecurity measures. Dairy producers are the focus of this study because they represent one of the largest animal producers in Washington State (WA) and because this group expressed a great deal of interest in addressing this challenge. Thus, the purposes of this study were to 1 ) describe knowledge and use of antibiotics and biosecurity practices among WA dairy producers, and 2) evaluate the effectiveness of a collaborative approach to promoting judicious use on dairy farms.

\section{MATERIALS AND METHODS}

\section{Assessment of Antibiotic Use and Biosecurity}

An Advisory Board comprising experts from Washington State University, Washington State Dairy Federation, Washington State Veterinary Medical Association, Washington State Department of Health, and University of Washington was convened. Under the Board's direction a survey was developed to quantify knowledge, attitudes, and practices. The survey included questions on herd characteristics (5), colostrum and calf 
management (21), disease prevention and management (28), biosecurity (18), antibiotic resistance (9), and demographics/overall farm management (6). Advisory Board members and several dairy veterinarians evaluated the survey for face and content validity, and 3 dairy producers pretested it. The survey instrument is available online as a supplement to this paper (http:// jds.fass.org/). The Social and Economic Sciences Research Center at Washington State University managed the data including collection, coding, entry, and cleaning.

A written survey was sent to all dairy farms in WA that were registered with the Department of Ecology, excluding the 3 farms that pretested the survey ( $\mathrm{n}=$ 589 total). Before mailing the survey, the Washington State Dairy Federation sent a letter to all dairy farms in the state informing them of the survey and encouraging their participation. The survey instrument was sent with a $\$ 5$ cash incentive, and it was followed by a postcard reminder. A second survey was mailed to nonresponders. Participants were asked to include a label from their calf milk replacer (if used) with the completed survey.

Based on the results of the survey, the Advisory Board identified key areas where judicious antibiotic use could be promoted and where biosecurity could be enhanced to prevent or reduce disease. These areas included 1) colostrum management and calf immunity testing, 2) use of medicated milk replacer, 3) diagnosis and treatment of common infectious diseases, and 4) preventing the introduction of pathogens onto the farm.

\section{Interventions}

The following interventions were undertaken.

1. In April 2004, the WA State Dairy Federation sent a letter to all registered dairies $(n=589)$ in the state urging them to cease using antibiotic-medicated milk replacer and issued a press release regarding this communication. This led to several articles appearing in agricultural newspapers distributed in multiple western states.

2. In August, October, and November 2004, newsletters were sent to all registered dairies in WA on the following topics: colostrum and calf management, diagnosis and treatment of common diseases, and controlling infections. The newsletters were sent by WA State Dairy Federation on behalf of the project, and displayed their logo in addition to the project logo (newsletters available as a supplement to this article online at http://jds.fass.org/).

3. The first newsletter offered dairy producers the opportunity to receive free kits for testing immunoglobulin levels in colostrum and kits for testing calves for adequate passive transfer of antibodies. Kits were sent to interested producers $(n=30)$ along with a brief survey regarding the ease of administering the test, the test results, and producers' reactions to the results. The goal of this intervention was to promote regular testing of calves, which allows the producer to modify his/her management practices for optimal calf immunity.

4. In December 2004, a spiral-bound reference manual on disease management and antibiotic use for dairy farms and an English-Spanish dictionary of dairy terms and phrases were sent to every registered WA dairy producer. The manual was compiled from a variety of published and unpublished sources. The manual contained bilingual protocols for diagnosing and treating common bovine diseases with spaces for a veterinarian to fill in drug names and dosages (available as a supplement to this article online at http://jds.fass.org/); lists of approved and unapproved drugs used in dairy cattle; information on judicious use of antibiotics, the valid veterinarian-client-patient relationship, prevention of infection, and enhancing immunity; and a list of medicated and nonmedicated milk replacers. The manual was designed to encourage producers to work with their veterinarian to appropriately diagnose disease and select appropriate treatment.

\section{Reassessment and Evaluation of Interventions}

In February 2005, written follow-up surveys were sent to the dairy producers who completed the initial survey, again with a $\$ 5$ cash incentive. This second survey contained some of the same questions from the first survey, new questions designed to gain more indepth information on issues discovered in the first survey, and 14 questions relating to producers' reactions to the interventions.

\section{Data Analyses}

Data was analyzed using SPSS version 12.0.1 (SPSS Inc., Chicago, IL). Simple frequencies were determined for all variables and associations between categorical variables were tested using $\chi^{2}$ statistics; for paired data using McNemar's $\chi^{2}$ test. Odds ratios (OR) were calculated using Mantel-Haenszel statistics, and were considered statistically significant for $P<0.01$.

\section{RESULTS}

Three hundred eighty-one $(65 \%)$ dairy producers completed the first survey (2003 survey). The second 
survey (2005 survey) was sent only to those who completed the first survey. Twenty-one participants from the first survey were ineligible for the second survey: 6 because they had removed the identification label from their first survey, and 15 because they were no longer in business in 2005 , leaving a sample of 360 . Two hundred ninety-two (81\%) completed the 2005 survey. Almost all respondents on both surveys (93 and 92\% per survey, respectively) were the farm owner. Other reported roles included manager, herdsman, and employee. Most farms reported a herd size of 100 to 499 cows. There were no statistically significant differences in herd size $(P=0.62)$ or years of dairy experience $(P=$ 0.47 ) between respondents on the first and second surveys.

\section{Colostrum and Calf Management}

Almost all (94\%) producers reported hand-feeding colostrum to calves in the first $24 \mathrm{~h}$ of life, and $32 \%$ also allow calves to nurse (Table 1). Sixty-seven percent estimated that calves received 2 to 4 quarts of colostrum and $30 \%$ estimated calves received more than 4 quarts in the first $24 \mathrm{~h}$. Although the large majority agreed that colostrum is important for calf growth (98\%), calf survival (99\%), milk production as an adult (85\%), and overall cost of raising calves (93\%), surprisingly few producers tested either colostrum quality ( $8 \%$; Table 1) or tested calves for passive transfer of antibodies (11\%; Table 2). Those who did not test colostrum cited unfamiliarity with the test (47\%) or insufficient personnel time $(26 \%)$ to conduct the tests; $18 \%$ stated it was not necessary to test colostrum. Almost all (93\%) recognized that colostrum quality varies from cow to cow, and three-fourths knew that simply getting some colostrum in the first $6 \mathrm{~h}$ of life does not guarantee adequate protection. One-fourth (24\%) of producers reported that they sent heifer calves off the operation to be raised by a calf rancher. Of these, only $14 \%$ reported that the calf rancher required proof of effective immune protection (passive transfer of antibodies) in calves.

Participants were asked if they fed heifer calves MR and if their MR was medicated with an antibiotic. Fortyone percent of the dairy producers reported not using MR, 30\% used nonmedicated MR, and 29\% used medicated MR. Of the 107 responders who reported using a medicated MR, however, 6 named a coccidiostat as the medication. Therefore, $27.5 \%$ of respondents reported using a noncoccidiostat antibiotic. Participants were also asked to submit a label from their MR and $28 \%$ $(\mathrm{n}=108)$ complied. There was over $90 \%$ agreement between self-reported use of medicated MR and label results. Almost all the medicated products cited contain both neomycin and oxytetracycline. Farms having 20 or more preweaned heifer calves were twice as likely to use MR products (OR 2.14, $P=0.001$ ), and more than twice as likely to use medicated MR (OR 2.44, $P=0.002)$ than smaller farms. Overall, $57 \%$ routinely fed waste milk to calves (Table 1); only 13\% pasteurized it before feeding (Table 2).

\section{Antibiotics Used for Disease Treatment and Prevention}

Participants were asked about the incidence and treatment of 5 common bovine infectious diseases. Of these, the most frequent problems reported in the 3 mo before the survey were mastitis and lameness, experienced by 89 and $80 \%$ of producers, respectively (Table 3 ). Diarrhea in calves (scours) was reported by $52 \%$ of producers, with 7 responders reporting that $50 \%$ or more of the calves were affected. One large operation having more than 200 preweaned heifers on site reported that scours affected $60 \%$. Participants were asked to report the antibiotics they used to treat these 5 conditions; those most frequently cited in cows were cephalosporins, penicillin, and oxytetracycline.

Less than one-third of respondents had written protocols for diagnosing (21\%) or treating $(27 \%)$ common medical conditions (Table 1), whereas the majority agreed that having such protocols could reduce errors (74\%) and reduce production losses (69\%; Table 4). In diagnosing mastitis, two-thirds of responders sometimes or always cultured milk from the affected quarters (Table 2); however, most producers based the decision for initiating antibiotic treatment of mastitis upon symptoms (89\%), rather than on positive culture results (19\%; Table 1).

Respondents were given a list of 14 antibiotics and asked to indicate if they used them for disease treatment or prevention (Table 5). The most commonly cited drugs used for treatment were penicillin, ceftiofur, and oxytetracycline. The most commonly cited drug used for disease prevention was chlortetracycline/sulfamethazine (cited by one-fourth of producers), followed by ceftiofur, oxytetracycline, and neomycin/oxytetracycline. Judging from the results of this question, most producers considered intramammary infusion to be a disease treatment rather than preventative practice.

Almost all producers injected an antibiotic preparation into the udder at the beginning of the dry period between lactation cycles, with the majority $(82 \%)$ of producers treating $100 \%$ of cows at dry-off (Table 1 ). The most common antibiotics used were cephapirin (used by 44\%), and a preparation containing a penicillin class drug (49\%). About half of producers utilized feed containing antibiotics; $14 \%$ did so seasonally, $22 \%$ did so during outbreaks of disease, and $16 \%$ did so for other 
Table 1. Self-reported use of herd health and biosecurity practices ( $n=381$ unless noted)

\begin{tabular}{|c|c|}
\hline Practice & $\begin{array}{l}\text { Use, \% of } \\
\text { producers }\end{array}$ \\
\hline \multicolumn{2}{|l|}{ Milk normally fed to newborn heifer calves in the first $24 h^{1}$} \\
\hline Colostrum by hand & 93.7 \\
\hline Nursing & 32.0 \\
\hline Colostrum replacer & 4.2 \\
\hline Waste milk & 2.9 \\
\hline Milk replacer & 2.4 \\
\hline Bulk tank milk & 1.3 \\
\hline \multicolumn{2}{|l|}{ Amount of colostrum heifer calves receive during the first $24 \mathrm{~h}$} \\
\hline Less than 2 quarts & 1.1 \\
\hline 2 quarts to 4 quarts & 67.3 \\
\hline More than 4 quarts & 30.1 \\
\hline Don't Know & 1.6 \\
\hline \multicolumn{2}{|l|}{ Usual method for storing colostrum if not used within $1 \mathrm{~h}$ of collection } \\
\hline Not stored & 11.9 \\
\hline Stored w/o refrigeration & 16.4 \\
\hline Stored in refrigerator & 32.8 \\
\hline Stored in freezer & 38.7 \\
\hline Other & 0.3 \\
\hline Test colostrum for immunoglobulin levels $=$ Yes & 7.5 \\
\hline Routinely feed waste milk to calves $=$ Yes & 57.2 \\
\hline \multicolumn{2}{|l|}{ Milk replacer medicated with an antibiotic } \\
\hline in $2003(\mathrm{n}=367)$ & 27.5 \\
\hline in $2005(\mathrm{n}=288)$ & 22.2 \\
\hline Have written protocols for diagnosing common medical conditions $=$ Yes & 21.0 \\
\hline Have written protocols for treating common medical conditions $=$ Yes & 27.3 \\
\hline \multicolumn{2}{|l|}{ Criteria used to determine the need for antibiotic treatment of mastitis ${ }^{1}$} \\
\hline Symptoms & 88.9 \\
\hline Positive on-farm test kit & 21.4 \\
\hline Positive culture results & 19.2 \\
\hline \multicolumn{2}{|l|}{ Percentage of cows treated with intramammary infusion at dry-off, $\%$} \\
\hline None & 7.1 \\
\hline 1 to 49 & 5.2 \\
\hline 50 to 99 & 6.0 \\
\hline 100 & 81.7 \\
\hline \multicolumn{2}{|l|}{ Age groups getting feed containing antibiotics ${ }^{1}$} \\
\hline Preweaned heifers & 27.3 \\
\hline Weaned heifers $<12$ mo & 24.9 \\
\hline 12 to $24 \mathrm{mo}$ & 3.7 \\
\hline Lactating cows & 2.9 \\
\hline Dry cows & 0.5 \\
\hline \multicolumn{2}{|l|}{ Conditions under which feed containing antibiotics is used ${ }^{1}$} \\
\hline Seasonally & 14.2 \\
\hline During outbreaks of disease & 21.9 \\
\hline Other & 15.7 \\
\hline \multicolumn{2}{|l|}{ Vaccinations ${ }^{1}$} \\
\hline Bovine viral diarrhea & 88.9 \\
\hline Inf. bovine rhinotracheitis & 89.9 \\
\hline Parainfluenza Type 3 & 84.8 \\
\hline Bovine resp. syncytial virus & 81.1 \\
\hline Salmonella & 40.9 \\
\hline E. coli mastitis & 61.5 \\
\hline Test newly purchased animals for infectious diseases before joining the herd $(\mathrm{n}=156)=$ Yes & 18.6 \\
\hline \multicolumn{2}{|l|}{ Time newly purchased animals separated before joining the herd $(n=148)$} \\
\hline Not separated & 66.2 \\
\hline Separated $24 \mathrm{~h}$ or less & 15.5 \\
\hline Separated 1 to $13 \mathrm{~d}$ & 10.1 \\
\hline Separated 14 to $27 \mathrm{~d}$ & 4.1 \\
\hline Separated 4 wk or longer & 4.1 \\
\hline Use calving pen for purposes other than calving $=$ Yes & 37.3 \\
\hline Use sick pen for purposes other than sick animals $=$ Yes & 43.5 \\
\hline Use the same equipment for handling feed and for handling waste $=$ Yes & 60.0 \\
\hline
\end{tabular}

\footnotetext{
${ }^{1}$ Responders were allowed to check more than one answer.
} 
Table 2. Reported frequency of health management and biosecurity practices on dairy operation

\begin{tabular}{|c|c|c|c|}
\hline \multirow[b]{2}{*}{ Practice } & \multicolumn{3}{|c|}{ Response } \\
\hline & Never & Sometimes & Always \\
\hline Pasteurize waste milk fed to calves $(\mathrm{n}=175)$ & 86.6 & 2.3 & 11.0 \\
\hline Add antibiotics to colostrum $(\mathrm{n}=295)$ & 98.3 & 1.4 & 0.3 \\
\hline Culture milk from affected quarter(s) of cows with mastitis $(\mathrm{n}=370)$ & 31.9 & 53.8 & 14.3 \\
\hline Test cows with mastitis with an on-farm mastitis test kit $(n=369)$ & 56.6 & 25.5 & 17.9 \\
\hline Require visitors to the farm to sign a $\log$ book $(n=264)$ & 93.6 & 5.7 & 0.8 \\
\hline Provide protective footwear to visitors $(n=265)$ & 66.0 & 25.7 & 8.3 \\
\hline If same equipment used for handling feed and waste, clean equipment after handling waste $(\mathrm{n}=226)$ & 4.9 & 19.5 & 75.7 \\
\hline
\end{tabular}

reasons. One-fourth of producers used medicated feed for weaned heifers under age 12 mo. Curiously, 11 producers $(3 \%)$ reported using medicated feed (oxytetracycline or chlortetracycline; Table 1) for lactating cows either seasonally or during outbreaks, which is not a permitted practice.

\section{Extra-Label Uses of Antibiotics}

Eighty-seven respondents (23\%) reported one or more unapproved or prohibited uses of an antibiotic. Some unapproved antibiotics can be given under the direction of a veterinarian, and such use is considered "extra- label," whereas prohibited antibiotics should not be used in any circumstance. The most commonly cited extra-label drug in 2003 was gentamicin, used by $16 \%$ of respondents for disease treatment. Three producers also reported using gentamicin for disease prevention. Of the 29 people who indicated gentamicin use on the 2005 survey, only 14 always did so under direction of a veterinarian. In 2003, 19 and $8 \%$ of producers reported using neomycin for disease treatment and prevention, respectively. On the 2005 survey, $9 \%$ of respondents $(n=26)$ reported using a neomycin/oxytetracycline combination in lactating cattle, and only $57 \%$ routinely did so under a veterinarian's guidance. Eight percent of

Table 3. Occurrence and treatment of common health problems in dairy herd ( $\mathrm{n}=381$ unless noted)

\begin{tabular}{|c|c|c|c|c|c|}
\hline Health problem & $\begin{array}{l}\text { Had } \\
\text { problem } \\
\text { in prior } \\
3 \mathrm{mo}^{1}(\%)\end{array}$ & $\begin{array}{l}\text { Mean \% } \\
\text { of animals } \\
\text { affected }^{2}\end{array}$ & $\begin{array}{l}\text { Maximum } \\
\% \text { of } \\
\text { animals } \\
\text { affected }^{3}\end{array}$ & $\begin{array}{l}\text { Treated } \\
\text { most } \\
\text { affected } \\
\text { animals } \\
\text { w/antibiotic }{ }^{4}(\%)\end{array}$ & $\begin{array}{l}\text { Most common } \\
\text { antibiotic } \\
\text { treatment }^{5} \\
\text { (frequency) }\end{array}$ \\
\hline Mastitis & 89.4 & 2.8 & 15 & $\begin{array}{l}88.1 \\
(\mathrm{n}=328)\end{array}$ & $\begin{array}{l}\text { Cephapirin }(39 \%) \\
\text { Pirlimycin }(18 \%) \\
\text { Penicillin }(18 \%)\end{array}$ \\
\hline Lameness & 80.4 & 3.6 & 30 & $\begin{array}{l}74.2 \\
(\mathrm{n}=295)\end{array}$ & $\begin{array}{l}\text { Ceftiofur }(45 \%) \\
\text { Penicillin }(28 \%) \\
\text { Oxytetracycline (12\%) }\end{array}$ \\
\hline Respiratory illness - cow & 36.4 & 0.4 & 10 & $\begin{array}{l}95.5 \\
(\mathrm{n}=134)\end{array}$ & $\begin{array}{l}\text { Ceftiofur }(51 \%) \\
\text { Penicillin }(16 \%) \\
\text { Oxytetracycline }(13 \%)\end{array}$ \\
\hline Respiratory illness - calf & 53.8 & 2.2 & 50 & $\begin{array}{l}97.0 \\
(\mathrm{n}=198)\end{array}$ & $\begin{array}{l}\text { Florfenicol }(27 \%) \\
\text { Tilmicosin }(20 \%) \\
\text { Ceftiofur }(18 \%)\end{array}$ \\
\hline Scours & 51.8 & 3.9 & 100 & $\begin{array}{l}84.2 \\
(\mathrm{n}=190)\end{array}$ & $\begin{array}{l}\text { Sulfa }(28 \%) \\
\text { Oxytetracycline (18\%) } \\
\text { Ceftiofur }(14 \%)\end{array}$ \\
\hline
\end{tabular}

\footnotetext{
${ }^{1}$ Numerator $=$ number of respondents who reported having the problem in prior $3 \mathrm{mo}$, denominator $=$ number of respondents who answered the question.

${ }^{2}$ Mean was calculated using $0 \%$ for those who reported not having the problem and the reported percentage of animals affected for those who reported having the problem.

${ }^{3}$ This number represents the one producer reporting the highest proportion of animals affected.

${ }^{4}$ Numerator $=$ number of respondents reporting that they treated most affected animals with an antibiotic, denominator $=$ number of respondents who reported having the problem in prior $3 \mathrm{mo}$.

${ }^{5}$ Numerator $=$ number of respondents who reported using the antibiotic as their most common treatment, denominator $=$ number of respondents who provided an antibiotic name.
} 
Table 4. Dairy producers' attitudes

\begin{tabular}{|c|c|c|c|c|c|}
\hline \multirow[b]{2}{*}{ Statement } & \multicolumn{5}{|c|}{ Response } \\
\hline & $\begin{array}{l}\text { Agree } \\
\text { strongly }\end{array}$ & $\begin{array}{l}\text { Agree } \\
\text { somewhat }\end{array}$ & $\begin{array}{l}\text { Disagree } \\
\text { somewhat }\end{array}$ & $\begin{array}{l}\text { Disagree } \\
\text { strongly }\end{array}$ & $\begin{array}{l}\text { Don't } \\
\text { know }\end{array}$ \\
\hline $\begin{array}{l}\text { If a cow has an infection that is resistant to antibiotics, this could be a threat } \\
\text { to the rest of my herd }(\mathrm{n}=373)\end{array}$ & 45.3 & 35.1 & 10.5 & 4.6 & 4.6 \\
\hline $\begin{array}{l}\text { If a cow has an infection that is resistant to antibiotics, this could be a threat } \\
\text { to my farm workers }(n=372)\end{array}$ & 8.3 & 25.3 & 29.6 & 23.1 & 13.7 \\
\hline The use of antibiotics in food-producing animals can impact human health $(\mathrm{n}=373)$ & 24.7 & 34.3 & 18.5 & 13.9 & 8.6 \\
\hline $\begin{array}{l}\text { Having written protocols for diagnosing and treating common infectious diseases } \\
\text { can help reduce errors }(\mathrm{n}=364)\end{array}$ & 34.6 & 39.3 & 7.1 & 7.4 & 11.5 \\
\hline $\begin{array}{l}\text { Having written protocols for diagnosing and treating common infectious diseases } \\
\text { can reduce loss of production }(n=362)\end{array}$ & 27.3 & 41.2 & 10.5 & 7.5 & 13.5 \\
\hline $\begin{array}{l}\text { Finding out if calves have adequate immune protection (passive transfer } \\
\text { of antibodies) is worth the time and expense of testing }(\mathrm{n}=286)\end{array}$ & 14.7 & 46.5 & 10.1 & 5.2 & 23.4 \\
\hline
\end{tabular}

respondents in 2005 reported using florfenicol and yet only about half $(48 \%)$ administered this extra-label drug under veterinarian direction. Finally, in 2005, $4.7 \%$ of producers reported using enrofloxacin.

\section{Biosecurity and Infection Control}

On the 2003 survey, more than one-third of producers (40\%) reported having purchased replacement animals in the previous $2 \mathrm{yr}$. The majority (66\%) did not implement any quarantine period for these animals despite almost unanimous agreement (99\%) with the statement that a calf purchased at auction could introduce disease onto their farm. Some producers (10\%) separated new animals from the rest of the herd for 1 to $13 \mathrm{~d}$, and only $8 \%$ imposed a quarantine period of $2 \mathrm{wk}$ or longer. Most producers $(81 \%)$ did not test new animals for infectious

Table 5. Percentage of dairy producers who use selected drugs for disease prevention and treatment $(\mathrm{n}=371)$ in $2003^{1}$

\begin{tabular}{lcl}
\hline Drug & Prevention & Treatment \\
\hline Penicillin G & 6.3 & 89.9 \\
Ampicillin & 0.5 & 26.5 \\
Amoxicillin & 2.2 & 28.6 \\
Ceftiofur & 8.6 & 87.8 \\
Erythromycin & 1.1 & 12.4 \\
Tylosin & 2.2 & 27.3 \\
Tilmicosin & 2.2 & 38.5 \\
Sulfachlorpyridazine & 0.3 & 10.2 \\
Sulfa drugs & 2.2 & 55.0 \\
Oxytetracycline HCl & 8.0 & 69.8 \\
Chlortetracycline/sulfamethazine & 25.8 & 23.9 \\
Neomycin/oxytetracycline & 7.6 & 18.9 \\
Gentamicin & 0.8 & 16.6 \\
Florfenicol & 2.5 & 41.2 \\
\hline
\end{tabular}

${ }^{1}$ The decision to classify an application as prevention or treatment was tallied from producers' responses. diseases before introducing them to the herd population (Table 1).

Over one-third of producers used their calving pen or sick pen for more than the designated purpose, and most respondents cited a lack of physical space or facilities as the reason for doing so. In addition, most (60\%) reported using the same equipment for handling feed and waste (Table 1), with most (76\%) always cleaning the equipment between uses (Table 2). More than $80 \%$ vaccinated against bovine viral diarrhea, infectious bovine rhinotracheitis, parainfluenza type 3 , and bovine syncytial virus, whereas $62 \%$ vaccinated against $E$. coli mastitis and less than half $(41 \%)$ vaccinated against Salmonella (Table 1). Reasons cited for not giving one or more vaccines included not believing that vaccination would be effective, or that there was no perceived threat of a particular disease.

Of those facilities that reported on-farm visitors (72\%), few reported having procedures in place to prevent visitors from inadvertently (or purposely) introducing pathogens. When security measures were implemented, they included providing protective clothing $(20 \%)$ or protective footwear (34\%; Table 2$)$. The majority of producers $(74 \%)$ sometimes or always had an employee accompany visitors during their entire visit to the farm. Almost all producers $(96 \%)$ indicated that they prohibited passage of rendering trucks through areas where animals were housed or fed.

\section{Perceptions Regarding Antibiotic Resistance}

More than one-third (37\%) of respondents believed that antibiotics that worked well in the past were no longer as effective for treating the same conditions. Almost all (86\%) claimed to know either a little or a lot 
about antibiotic resistance, and $72 \%$ were able to select the correct definition of antibiotic resistance when given several choices. Most agreed that a resistant infection in a cow could threaten the rest of the herd (80\%), that antibiotics become less effective the more they are used (74\%), and that the use of antibiotics in food-producing animals could impact human health (59\%; Table 4). Only $34 \%$ believed that a resistant infection in a cow could threaten farm workers. Most (78\%) felt that milk production would decrease if they did not use antibiotics for dry-cow treatment.

\section{Initial Assessment of Intervention Strategies}

A follow-up survey was conducted in 2005, 19 mo after the first survey and 2 mo after the final intervention packet was mailed to producers. It was completed by $81 \%$ of eligible producers who completed the first survey. In 2005, $22.2 \%$ of producers reported using medicated milk replacer (after correcting for use of coccidiostats, which were not considered medicated MR), as compared with $27.5 \%$ in $2003(P=0.12)$. Half $(51 \%)$ of those who reported using medicated MR in 2003 reported not using it in 2005 (they had switched to either a nonmedicated product or were not using MR at all). In contrast, only $12 \%$ of producers who reported not using medicated MR in 2003 had begun using a medicated MR by 2005 . This analysis, by necessity, only included producers who answered this question on both surveys $(\mathrm{n}=278)$; although the difference was large (4 times as many producers stopped using medicated MR as started using it), this matched analysis was not statistically significant for $\alpha=0.01(P=0.059)$. Of those who reported they changed their MR product, the most common reason was cost (25\%), followed by a veterinarian's recommendation (17\%); $12 \%(\mathrm{n}=5)$ of those who made a change did so based on information from the WA State Dairy Federation. Most producers (63\%) recalled receiving the WA State Dairy Federation letter regarding milk replacer, and most of these $(66 \%)$ recalled that the letter's main message was that antibiotics in MR could be harmful. Most also recalled receiving the other intervention mailings, and 90 and $82 \%$ felt that the newsletters and reference manual, respectively, were somewhat or very useful. Most (68\%) respondents reported having one or more Hispanic workers (mean 4.6, range: 0 to 85 ) and the majority of producers (61\%) felt that the English-Spanish pocket dairy dictionary was somewhat or very useful.

Many respondents claimed to have made changes in practice in the prior year, including decreased use of antibiotics (37\%), change in vaccination program (27\%), additional biosecurity practices (19\%), and colostrum management (22\%; Table 6). In addition, $22 \%$ reported that their veterinarian had spoken with them about antibiotic resistance. Over one-fourth (28\%) claimed to have worked with their veterinarian to establish disease treatment protocols for the herd, and one-third of these used the examples sent as part of the intervention. Strangely, this change was not reflected in the overall proportion of producers who reported having disease treatment protocols, which only rose from $27 \%$ in 2003 to $30 \%$ in 2005.

Data were received from 12 of the producers who requested colostrum or calf blood test kits. Colostrum testing determines the quality of colostrum based on immunoglobulin levels, and calf blood testing determines if a 1- to 6-d-old calf received adequate passive transfer of antibodies via colostrum. The 12 producers reported data on a total of 29 calves, $17 \%$ of which failed passive transfer. Of 33 colostrum samples tested, $21 \%$ had inadequate IgG levels. The majority of respondents (75\%) indicated that they would be likely to test in the future.

Producers were invited to write in their opinions about antibiotics and milk replacer. Those who supported the use of medicated MR argued that they had good experiences with it $(n=6)$ or believed it contributed to disease control $(n=4)$, and some expressed unease with making a change $(n=2)$. Opponents of medicated MR commented that calves that get adequate colostrum $(n=3)$ or are raised in a clean environment $(n=2)$ should not need antibiotics in MR, and that medicated MR can disrupt helpful bacteria in the gut $(n=1)$ or interfere with immunity $(n=2)$. Opponents also indicated that antibiotics should not be used for disease prevention $(n=4)$, that they are not necessary in MR $(\mathrm{n}=8)$, or that adding antibiotics to MR is an inappropriate practice $(n=4)$ that could lead to resistance $(n=2)$.

There was no meaningful change in the proportion of producers who tested newly purchased animals for disease before introducing them into the herd, quarantined newly purchased animals, used the calving pen for other purposes, or used the sick pen for other purposes.

\section{DISCUSSION}

The purpose of this study was to evaluate dairy producers' knowledge of antibiotics and biosecurity practices while evaluating a collaborative approach to promoting judicious antibiotic use on dairy farms. It is clear to the authors of this study that the high response rate to the survey (65\% on first survey) was due to the support of the WA State Dairy Federation. The high response rate is further evidence that producers are genuinely concerned about this issue. The individuals 
Table 6. Percentage of dairy producers self-reporting changes in practice, $2005(\mathrm{n}=$ number of respondents)

\begin{tabular}{lr}
\hline Self-reported change in practice & Number $(\%)$ \\
\hline In past year, changed to a milk replacer containing an antibiotic (other than a coccidiostat) $(\mathrm{n}=280)$ & $10(3.6)$ \\
In past year, changed to a milk replacer NOT containing an antibiotic (other than a coccidiostat) $(\mathrm{n}=277)$ & $28(10.1)$ \\
In past year, started using disease diagnosis/management protocols $(\mathrm{n}=274)$ & $31(11.3)$ \\
In past year, decreased use of antibiotics $(\mathrm{n}=277)$ & $102(36.8)$ \\
In past year, started using probiotics $(\mathrm{n}=280)$ & $45(16.1)$ \\
In past year, changed colostrum management practice $(\mathrm{n}=281)$ & $61(21.7)$ \\
In past year, changed herd vaccination program $(\mathrm{n}=286)$ & $76(26.6)$ \\
In past year, started new biosecurity practices $(\mathrm{n}=282)$ & $34(19.1)$ \\
At least one of these changes influenced by Dairy Federation's letter re: milk replacer $(\mathrm{n}=274)$ & $35(12.8)$ \\
At least one of these changes influenced by informational mailings from Animal Health on WA Dairy Farms Project $(\mathrm{n}=268)$ & $39(14.6)$ \\
In past 6 mo, worked with veterinarian to establish disease treatment protocols $(\mathrm{n}=282)$ & $80(28.4)$ \\
If yes to above, used protocol examples sent by the Dairy Federation $(\mathrm{n}=78)$ & $23(29.5)$ \\
In the past 6 mo, veterinarian talked with producer about how to preserve the power of antibiotics and/or the problem of & $61(21.8)$ \\
antibiotic resistance $(\mathrm{n}=280)$ & \\
\hline
\end{tabular}

involved in this study were in general agreement that judicious use of antibiotics is in the best interest of both human and animal health and welfare.

Antibiotics have 3 primary functions in animal agriculture: growth promotion, disease prevention, and disease treatment (Aarestrup, 2005). In the case of dairy production, studies are lacking that substantiate a relationship between antibiotic-induced growth promotion in calves and lifetime milk production. Clearly, disease prevention has a direct benefit both in terms of increased productivity and in terms of avoiding additional antibiotic use that might be needed for therapy. Thus, the question becomes how to implement alternative management practices that reduce the need (real or perceived) for nontherapeutic use of antibiotics and ultimately reduce the need for therapeutic antibiotics in animal agriculture. In this study of self-reported practices, the percentage of producers that fed medicated MR to dairy calves was $28 \%$ in 2003 and $22 \%$ in 2005 . This is markedly lower than the $70 \%$ of Pennsylvania dairy farms reported by Sawant et al. (2005). In the current study, most producers agreed on the importance of biosecurity, colostrum management, and basic health care and disease prevention (e.g., vaccines). The relatively low-cost educational effort suggested that it is possible to emphasize and encourage these practices while discouraging reliance on medicated milk replacers.

The survey data demonstrated that in addition to therapeutic use, antibiotics were also used for preventive purposes, which were commonly given at subtherapeutic doses. The most common preventative uses included using medicated MR for scours prevention, using medicated feed seasonally or during disease outbreaks, and dry-cow treatment of mastitis prevention (conventionally a therapeutic dose). With respect to medicated MR, it is important to note that more than two-thirds of farms in WA are not using medicated MR, so it ap- pears that this practice is not necessary to maintain productivity. Dry-cow treatment by intramammary infusion of antibiotics can play an important role in preventing mastitis and there is some debate about the degree to which this activity contributes to the emergence of antibiotic-resistant mastitis pathogens (Erskine et al., 2002; Makovec and Ruegg, 2003), or whether the community is defining resistance in an appropriate manner for these disease agents (Fernanda and Ruegg, 2005). It is worth noting that nonantibiotic teat sealers used as dry-off treatment can be effective in preventing mastitis in herds managed for low SCC (Twomey et al., 2000; Huxley et al., 2002). Furthermore, when mastitis is indicated, gram-negative infections are often self-limiting and it may behoove the producer to avoid using antibiotic treatment to speed return of lactating animals to production (Sears and McCarthy, 2003a).

It is concerning that the majority of dairy producers administered antibiotics without the benefit of written treatment protocols (other than manufacturer's directions); only $27 \%$ had written protocols, which concurs with the findings of $21 \%$ by Sawant et al. (2005) in Pennsylvania. Given the frequency of antibiotic therapy on the dairy farm and the potential involvement of workers in administering antibiotics (some of whom might have limited English-language skills), a lack of written protocols could lead to variability in therapy as well as inappropriate drug selection, dosing, or scheduling, which can promote the selection of resistant bacteria. Relatively simple on-farm diagnostic procedures might also be implemented to help identify mastitis cases that need treatment vs. those that could be returned to production after a short recovery period (Sears and McCarthy, 2003a,b)

A large percentage (23\%) of WA dairy producers reported at least one extra-label use of antibiotics, and it appeared that only about half routinely involved their 
veterinarian in these decisions, despite a legal requirement to do so (http://www.avma.org/scienact/amduca/ amduca1.asp, accessed August 2, 2005). Although extra-label use of gentamicin is legal, the American Veterinary Medical Association (AVMA) and the American Association of Bovine Practitioners (AABP) recommend against extra-label use of aminoglycosides (http:// www.avma.org/policies/aminoglycoside.asp, accessed August 18, 2005; Gatz Riddell, Executive Vice President, AABP, personal communication, August 17, 2005), to which gentamicin and neomycin belong. Neomycin is only approved for oral or feed additive use in nonlactating cattle. The use of enrofloxacin is prohibited in dairy cattle (http://www.fda.gov/cvm/CVM_Up dates/NOELUUP.HTMl, accessed August 26, 2005).

In Pennsylvania, Sawant et al. (2005) found that 79\% of dairy producers administered extra-label medication only on orders from a veterinarian. Some of the drug uses cited by participants in the present study were not only extra-label, but are recommended against for any use by the AABP or AVMA (e.g., gentamicin), or are prohibited outright (e.g., enrofloxacin). Although these uses may constitute a small portion of overall antibiotic use, their application is concerning and is an area where intervention is needed. Producers need to understand the rationale behind restricting certain drugs, and the importance of veterinarian input in nonstandard drug use and alternative therapies. Enhancing the veterinarian's involvement in antibiotic decision-making on the farm is a key component of improving judicious use. Although most producers (94\%) said the person they relied upon the most when facing animal health management problems was a veterinarian, a number of producers cited the cost of or access to veterinary services as barriers. Providing written templates for disease diagnosis and treatment, which the herd veterinarian can customize to the farm by entering drugs and dosages, might be a cost-effective tool for obtaining veterinarian input into treatment decisions (samples in English and Spanish are available as a supplement to this article online at http://jds.fass.org/).

There is a need to focus producer attention on enhancing immunity and preventing infection, both of which can significantly reduce the need for preventive and therapeutic antibiotics (Berge et al., 2005b). Improvements could probably be directed to colostrum management including testing of colostrum quality and calf immunity; vaccination, testing, and quarantine of newly purchased animals; and separation of sick animals. Most producers agreed somewhat that testing for adequate immune protection was worth the time and expense, but nearly $90 \%$ did not test calves. Several farms were visited and assistance was provided for calf testing; in most cases the producers expressed surprise at the poor level of transfer. The limited testing of passive transfer was not meant to be representative of Washington State dairies. Indeed, most producers reported that they used recommended practices (feeding by hand, $>2$ quarts, and cold storage). Nevertheless, the limited testing did indicate that improvements could be made with respect to passive immunity and that a combination of both education and demonstration of calf immunity on the farm may be needed to convince producers to adopt routine testing and adaptive management. It is possible that periodic testing could be implemented at the level of individual operations to help evaluate management practices.

Interestingly, for the initial survey, more than onethird of study participants perceived a decrease in antibiotic effectiveness on their operations. Whether this perception was due to antibiotic resistance, a change in the predominant pathogens, or media attention is not known. A few studies have found no increase in antibiotic resistance in mastitis pathogens from dairy cattle in the Midwest (Erskine et al., 2002;; Makovec and Ruegg, 2003). The National Antimicrobial Resistance Monitoring System reports increased resistance to a number of drugs in diagnostic bovine Salmonella isolates (http://ars.usda.gov/Business/docs.htm?docid= 6750 , accessed January 2, 2006). There is a lack of geographically consistent historic and current surveillance data upon which to determine actual trends in resistance.

Many participants commented on proposals to ban certain uses of antibiotics. The dairy industry is justifiably concerned about antibiotics, from the perspective of legal restrictions as well as bacterial resistance. In addition, the cost of production is an ever-present concern in agriculture, and there is a need to balance the cost of drugs against possible production losses. If subtherapeutic uses play a large role in selecting resistant organisms (especially multidrug-resistant strains), then the cost becomes higher as newer and more expensive drugs are needed to replace obsolete options.

Producers' demonstrated knowledge of antibiotic resistance and their attitudes regarding the impact of antibiotic use and antibiotic resistance indicated that they see antibiotics as a very important resource. Participants indicated that colostrum management is very important to calf survival and growth, they understood that disease could be introduced to the farm by purchased animals, and they recognized that written management protocols could reduce production losses. However, these attitudes were not reflected in their practices. Participants indicated satisfaction with their current practices and in general did not appear to perceive any major problems. This is similar to the case 
in human medicine in which practitioners perceive the importance of judicious antibiotic use and that antibiotic resistance is a national problem, but fewer practitioners perceive their institution as contributing to the problem (Brinsley et al., 2005).

Like any self-reported intervention effort, the present study is potentially burdened with several difficulties and biases. Behavior change theories indicate that people undergo change in stages; with the early stages involving recognition that change is required (Prochaska et al., 1997). Therefore, one should not expect significant changes to result after a basic educational intervention such as that conducted in the present study. Indeed, there did not appear to be significant change in the practices before and after the intervention. However, on the second survey, many producers claimed to have reduced their antibiotic use and improved biosecurity. There are several possible explanations for this discrepancy. Producers might have made real changes in practices that were not measured. Indeed, free text comments written by participants indicated changes in practices that were not surveyed, such as enhanced environmental cleaning, change in teat cleaning practice, keeping a closed herd, changes in bedding, and use of gloves for handling animals. The Hawthorne effect, whereby subjects change their behavior when being observed, might have led some respondents to exaggerate the changes they had made. However, the fact that producers reacted favorably to the resource materials provided through intervention and claimed to make changes indicates they are open to considering improvements. Similar positive responses have been found when education campaigns have been conducted in human medicine (Kiang et al., 2005).

Self-reported data are subject to a number of limitations, including prevarication and the Hawthorne effect. In addition, in some cases the people completing the surveys might not have complete knowledge of the practices occurring on their operations, particularly on large farms. There could be selection bias, whereby producers with a greater interest in preserving antibiotics might be more likely to have completed the survey and these producers might implement more control measures; this would be most likely to bias the results toward more judicious antibiotic use.

\section{CONCLUSIONS}

The majority of dairy producers (52 to 89\%) who participated in this study indicated some kind of active infectious disease problem and $37 \%$ perceived a decline in the effectiveness of antibiotics. Twenty-eight percent of WA producers use medicated MR, which is considerably lower than the $70 \%$ reported for Pennsylvania.
Although only $23 \%$ reported extra-label use of antibiotics in 2003, further probing in 2005 indicated that veterinary involvement in these uses is not universal. Only $21 \%$ of producers reported using written diagnosis protocols and $27 \%$ reported using treatment protocols at their facilities. In response to intervention efforts, the majority of producers (82 to $90 \%$ ) indicated that the materials provided by this project were useful and 19 to $37 \%$ reported changes in management practices to enhance animal health and welfare while practicing more judicious use of antibiotics. Further research should focus on identifying and testing creative management practices that lead to improved antibiotic stewardship while improving animal health and reducing overall costs to producers.

\section{ACKNOWLEDGMENTS}

We are grateful to our Advisory Board, and in particular Dale Hancock, for assistance with development of this project. Jay Gordon and Gloria Edwards from the WA State Dairy Federation greatly facilitated our efforts. The study was funded by a grant from the WA Attorney General's Office Vitamins Settlement Fund. In-kind support was provided by the WA State Dairy Federation, Midland BioProducts (Boone, IA), the WA Dairy Products Commission, and the Agricultural Animal Health Program at the College of Veterinary Medicine (Pullman, WA). The study was approved by the WA State University Institutional Review Board.

\section{REFERENCES}

Aarestrup, F. M. 2005. Veterinary drug usage and antimicrobial resistance in bacteria of animal origin. Basic Clin. Pharmacol. Toxicol. 96:271-281.

Aarestrup, F. M., A. M. Seyfarth, H. D. Emborg, K. Pedersen, R. S. Hendriksen, and F. Bager. 2001. Effect of abolishment of the use of antimicrobial agents for growth promotion on occurrence of antimicrobial resistance in fecal enterococci from food animals in Denmark. Antimicrob. Agents Chemother. 45:2054-2059.

Alcaine, S. D., S. S. Sukhnanand, L. D. Warnick, W. L. Su, P. McGann, P. McDonough, and M. Wiedmann. 2005. Ceftiofur-resistant Salmonella strains isolated from dairy farms represent multiple widely distributed subtypes that evolved by independent horizontal gene transfer. Antimicrob. Agents Chemother. 49:40614067.

Anderson, A. D., J. M. Nelson, and F. J. Angulo. 2003. Public health consequences of use of antimicrobial agents in food animals in the United States. Microb. Drug Resist. 9:373-379.

Andrews, A. H. 2000. Calf health. Pages 1-14 in The Health of Dairy Cattle. A. H. Andrews, ed. Blackwell Science, Oxford, UK.

Angulo, F. J., V. N. Nargund, and T. C. Chiller. 2004. Evidence of an association between use of antimicrobial agents in food animals and antimicrobial resistance among bacteria isolated from humans and the human health consequences of such resistance. J. Vet. Med. B51:374-379.

Arthington, J. D. 2001. Technologies for delivering passive immunity to newborn calves. Pages 80-90 in Proc. 12th Annu. Florida Ruminant Nutrition Symp., Ona, Florida. Univ. Florida, Gainesville.

Aubry-Damon, H., K. Grenet, P. Sall-Ndiaye, D. Che, E. Cordeiro, M. E. Bougnoux, E. Rigaud, Y. Le Strat, V. Lemanissier, L. Armand- 
Lefevre, D. Delzescaux, J. C. Desenclos, M. Lienard, and A. Andremont. 2004. Antimicrobial resistance in commensal flora of pig farmers. Emerg. Infect. Dis. 10:873-879.

Barrington, G. M., J. M. Gay, and J. F. Everman. 2002. Biosecurity for neonatal gastrointestinal diseases. Vet. Clin. North Am. Food Anim. Pract. 18:7-34.

Berge, A. C., P. Lindeque, D. A. Moore, and W. M. Sischo. 2005a. A clinical trial evaluating prophylactic and therapeutic antibiotic use on health and performance of preweaned calves. J. Dairy Sci. 88:2166-2177.

Berge, A. C. B., E. R. Atwill, and W. M. Sischo. 2005b. Animal and farm influences on the dynamics of antibiotic resistance in faecal Escherichia coli in young calves. Prev. Vet. Med. 69:25-38.

Brinsley, K., R. Sinkowitz-Cochran, and D. Cardo. 2005. An assessment of issues surrounding implementation of the Campaign to Prevent Antimicrobial Resistance in Healthcare Settings. Am. J. Infect. Control 33:402-409.

Casewell, M., C. Friis, E. Marco, P. McMullin, and I. Phillips. 2003. The European ban on growth-promoting antibiotics and emerging consequences for human and animal health. J. Antimicrob. Chemother. 52:159-161.

Delsol, A. A., J. Sunderland, M. J. Woodward, L. Pumbwe, L. J. Piddock, and J. M. Roe. 2004. Emergence of fluoroqinolone resistance in native Campylobacter coli population of pigs exposed to enrofloxacin. J. Antimicrob. Chemother. 53:872-874.

Dodd, F. H., and J. M. Booth. 2000. Mastitis and milk production. Pages $213-255$ in The Health of Dairy Cattle. A. H. Andrews, ed. Blackwell Science, Oxford, UK.

Donovan, D. C., S. T. Franklin, C. C. L. Chase, and A. R. Hippen. 2002. Growth and health of Holstein calves fed milk replacers supplemented with antibiotics or Enteroguard. J. Dairy Sci. 85:947-950.

Dunlop, R. H., S. A. McEwen, A. H. Meek, R. C. Clarke, W. D. Black, and R. M. Friendship. 1998. Associations among antimicrobial drug treatments and antimicrobial resistance of fecal Escherichia coli of swine on 34 farrow-to-finish farms in Ontario, Canada. Prev. Vet. Med. 34:283-305.

Erskine, R. J., R. D. Walker, C. A. Bolin, P. C. Bartlett, and D. G. White. 2002. Trends in antibacterial susceptibility of mastitis pathogens during a seven-year period. J. Dairy Sci. 85:1111-1118.

Faust, M. A., M. L. Kinsel, and M. A. Kirkpatrick. 2001. Characterizing biosecurity, health, and culling during dairy herd expansions. J. Dairy Sci. 84:955-965.

Fernanda, G. H. H., and P. L. Ruegg. 2005. Relationship between antimicrobial susceptibility of clinical mastitis pathogens and treatment outcome in cows. J. Am. Vet. Med. Assoc. 227:14611468.

Fossler, C. P., S. J. Wells, J. B. Kaneene, P. L. Ruegg, L. D. Warnick, J. B. Bender, L. E. Eberly, S. M. Godden, and L. W. Halbert. 2005a. Herd-level factors associated with isolation of Salmonella in a multi-state study of conventional and organic dairy farms. I. Salmonella shedding in cows. Prev. Vet. Med. 70:257-277.

Fossler, C. P., S. J. Wells, J. B. Kaneene, P. L. Ruegg, L. D. Warnick, J. B. Bender, L. E. Eberly, S. M. Godden, and L. W. Halbert. 2005b. Herd-level factors associated with isolation of Salmonella in a multi-state study of conventional and organic dairy farms. II. Salmonella shedding in calves. Prev. Vet. Med. 70:279-291.

Gay, C. C. 1984. The role of colostrums in managing calf health. Bovine Pract. 16:79-84.

Grooms, D. L. 2004. Reproductive consequences of infection with bovine viral diarrhea virus. Vet. Clin. North Am. Food Anim. Pract. 20:5-19.

Hancock, D. D., T. Besser, J. Gay, D. Rice, M. Davis, and C. Gay. 2000. The global epidemiology of multiresistant Salmonella enterica serovar Typhimurium DT104. Pages 217-243 in Emerging Diseases of Animals. C. Brown and C. Bolin, ed. ASM Press, Washington, DC.

Heinrichs, A. J., S. J. Wells, and W. C. Losinger. 1995. A study of the use of milk replacers for dairy calves in the United States. J. Dairy Sci. 78:2831-2837.

Humphrey, T. J., F. Jorgensen, J. A. Frost, H. Wadda, G. Domingue, N. C. Elviss, D. J. Griggs, and L. J. Piddock. 2005. Prevalence and subtypes of ciprofloxacin-resistant Campylobacter spp. in commercial poultry flocks before, during, and after treatment with fluoroquinolones. Antimicrob. Agents Chemother. 49:690698

Huxley, J. N., M. J. Green, L. E. Green, and A. J. Bradley. 2002. Evaluation of the efficacy of an internal teat sealer during the dry period. J. Dairy Sci. 85:551-561.

Kiang, K. M., B. A. Kieke, K. Como-Sabetti, R. Lynfield, R. E. Besser, and E. A. Belongia. 2005. Clinician knowledge and beliefs after statewide program to promote appropriate antimicrobial drug use. Emerg. Infect. Dis. 11:904-911.

Levy, S. B. 1978. Emergence of antibiotic-resistance bacteria in the intestinal flora of farm inhabitants. J. Infect. Dis. 137:689-690.

Losinger, W. C., S. J. Wells, L. P. Garber, and H. S. Hurd. 1995. Management factors related to Salmonella shedding by dairy heifers. J. Dairy Sci. 78:2464-2472.

Makovec, J. A., and P. L. Ruegg. 2003. Antimicrobial resistance of bacteria isolated from dairy cow milk samples submitted for bacterial culture: 8,905 samples (1994-2001). J. Am. Vet. Med. Assoc. 222:1582-1589.

Mathew, A. G., K. N. Garner, P. D. Ebner, A. M. Saxton, R. E. Clift, and S. Liamthong. 2005. Effects of antibiotic use in sows on resistance of $E$. coli and Salmonella enterica Typhimurium in their offspring. Foodborne Pathog. Dis. 2:212-220.

Mellon, M., C. Benbrook, and K. L. Benbrook. 2001. Hogging it: Estimates of antimicrobial abuse in livestock. UCS Publications, Cambridge, MA.

Morrill, J. L., J. M. Morrill, A. M. Feyerherm, and J. F. Laster. 1995. Plasma proteins and a probiotic as ingredients in milk replacer. J. Dairy Sci. 78:902-907.

Nocek, J. E., D. G. Braund, and R. G. Warner. 1984. Influence of neonatal colostrum administration, immunoglobulin, and continued feeding of colostrum on calf gain, health, and serum protein. J. Dairy Sci. 67:319-333.

NRC. 1998. The use of drugs in food animals: Benefits and risks. National Research Council, National Academy Press, Washington, DC.

Poppe, C., L. C. Martin, C. L. Gyles, R. Reid-Smith, P. Boerlin, S. A. McEwen, J. F. Prescott, and K. R. Forward. 2005. Acquisition of resistance to extended-spectrum cephalosporins by Salmonella enterica subsp. enterica serovar Newport and Escherichia coli in the turkey poult intestinal tract. Appl. Environ. Microbiol. 71:1184-1192

Prochaska, J. O., C. A. Redding, and K. E. Evers. 1997. The transtheoretical model and states of change. Pages 60-84 in Health Behavior and Health Education: Theory, Research, and Practice. 2nd ed. K. Glanz, F. M. Lewis, and B. K. Rimer, ed. Jossey-Bass, San Francisco, CA.

Quigley, J. D., J. J. Drewry, L. M. Murray, and S. J. Ivey. 1997. Body weight gain, feed efficiency, and fecal scores of dairy calves in response to galactosyl-lactose or antibiotics in milk replacers. J. Dairy Sci. 80:1751-1754.

Randall, L. P., D. J. Eaves, S. W. Cooles, V. Ricci, A. Buckley, M. J. Woodward, and L. J. Piddock. 2005. Fluoroquinolone treatment of experimental Salmonella enterica serovar Typhimurium DT104 infections in chickens selects for both gyrA mutations and changes in efflux pump gene expression. J. Antimicrob. Chemother. 56:297-306.

Sato, K., P. C. Bartlett, and M. A. Saaed. 2005. Antimicrobial susceptibility of $E$. coli isolates from dairy farms using organic vs. conventional methods. J. Am. Vet. Med. Assoc. 226:589-594.

Sawant, A. A., and B. M. Jayarao. 2002. Milk replacers and bacterial antibiotic resistance. Herd Health Memo, December issue, Pennsylvania State University Cooperative Extension, College of Agricultural Sciences. University Park.

Sawant, A. A., L. M. Sordillo, and B. M. Jayarao. 2005. A survey on antibiotic usage in dairy herds in Pennsylvania. J. Dairy Sci 88:2991-2999

Sears, P. M., and K. K. McCarthy. 2003a. Diagnosis of mastitis for therapy decisions. Vet. Clin. North Am. Food Anim. Pract. 19:93-108

Sears, P. M., and K. K. McCarthy. 2003b. Management and treatment of staphylococcal mastitis. Vet. Clin. North Am. Food Anim. Pract. 19:171-185. 
Takahashi, T., K. Ishihara, A. Kojima, T. Asai, K. Harada, and Y. Tamura. 2005. Emergence of fluoroquinolone resistance in Campylobacter jejuni in chickens exposed to enrofloxacin treatment at the inherent dosage licensed in Japan. J. Vet. Med. B Infect. Dis. Vet. Public Health 52:460-464.

Threfall, E. J., L. R. Ward, J. A. Frost, and G. A. Willshaw. 2000. The emergence and spread of antibiotic resistance in food-borne bacteria. Int. J. Food Microbiol. 62:1-5.

Twomey, D. P., A. I. Wheelock, J. Flynn, W. Y. Meaney, C. Hill, and R. P. Ross. 2000. Protection against Staphylococcus aureus mastitis in dairy cows using a bismuth-based teat seal containing the bacteriocin, lacticin 3147. J. Dairy Sci. 83:1981-1988.

USDA. 2003a. Dairy 2002 Part II: Changes in the United States dairy industry, 1991-2002. APHIS Publication no. N388.0603, Fort Collins, CO.

USDA. 2003b. Dairy 2002 Part III: Reference of Dairy Cattle Health and Health Management practices in the United States, 2002. APHIS Publication no. N400.1203, Fort Collins, CO. van Schaik, G., Y. H. Schukken, M. Nielen, A. A. Dijkhuizen, H. W. Barkema, and G. Benedictus. 2002. Probability of and risk factors for introduction of infectious diseases into Dutch SPF dairy farms: A cohort study. Prev. Vet. Med. 54:279-289.

Weaver, A. D. 2000. Lameness. Pages 149-202 in The Health of Dairy Cattle. A. H. Andrews, ed. Blackwell Science, Oxford, UK.

Weaver, D. M., J. W. Tyler, D. C. VanMetre, D. E. Hostetler, and G. M. Barrington. 2000. Passive transfer of colostral immunoglobulins in calves. J. Vet. Intern. Med. 14:569-577.

Witte, W. 1998. Medical consequences of antibiotic use in agriculture. Science 279:996-997.

Wittum, T. E., and L. J. Perino. 1995. Passive immune status at postpartum hour 24 and long-term health and performance of calves. Am. J. Vet. Res. 56:1149-1154.

Wray, C., J. N. Todd, and M. Hinton. 1987. Epidemiology of Salmonella typhimurium infection in calves: Excretion of S. typhimurium in the faeces of calves in different management systems. Vet. Rec. 121:293-296. 